\title{
CASE CONTROL STUDY TO DETERMINE THE FACTORS ASSOCIATED WITH LEPROSY IN THE SENE DISTRICT, BRONG AHAFO REGION OF GHANA
}

\author{
A. A. OFOSU ${ }^{1}$ and G.Y. BONSU ${ }^{2}$ \\ 1Sene District Hospital, PO Box 35, Kwame Danso, Brong Ahafo Region, Ghana, 2Ghana Health Service, \\ Eastern Regional Health Directorate, Koforidua, Ghana
}

Corresponding Author: Dr Anthony A. Ofosu

Conflict of Interest: None declared

\section{SUMMARY}

Introduction: There are currently an estimated 10-12 million cases of leprosy in the world. .In Sene District of the Brong Ahafo Region of Ghana the prevalence of leprosy is 2.4/10,000 of the population. Most of these cases are children, indicating that new infections are still occurring in the communities.

Objectives: To identify factors associated with leprosy in the Sene District in order to implement an effective strategy to eliminate leprosy from the district.

Design: Case-control study.

Method: The cases were selected from a register of active leprosy cases. Controls were matched for age, and sex. For every one case identified two controls were selected.

Results: Of the twenty four cases identified, eighteen $(75 \%)$ were paucibacillary and six (25\%) were multibacillary leprosy. Most of the leprosy lesions were found on the trunk (25\%) and upper limbs (37.5\%). 13(54.2\%) of the cases were under twenty years old. From the study, contact with someone with leprosy in the same house is associated with having leprosy. (OR -3.4 95\%CI 1.09-10.8 p=0.017) . Not having BCG vaccination is associated with having leprosy (OR 11 95\%CI 2.12- 76.17) $\mathrm{p}=0.0005$ ).

Conclusion: The findings confirm that close contact with a patient with leprosy facilitates transmission of $M$. leprae. To reduce leprosy in the Sene District there is the need to increase BCG vaccination coverage in children and ensure that all contacts of cases are thoroughly screened for the disease and treated. Health workers in the district need to be trained to identify leprosy lesions.

Keywords: Leprosy, case control study, M. leprae, transmission, Ghana

\section{INTRODUCTION}

Leprosy is caused by infection with Mycobacterium leprae chiefly affecting the skin and peripheral nerves. Multibacillary patients are the main source of infection to other humans, with the main mode of leprosy
Email: Anthony.ofosu@ghsmail.org

transmission generally believed to be through droplets from coughing and sneezing ${ }^{1}$. As there is no effective vaccination against leprosy, but a full $85 \%$ of people are naturally immune to the disease, while $15 \%$ may get leprosy if exposed to the leprosy bacilli. ${ }^{1}$

The reactions that result in loss of nerve function are a major cause of the chronic disability often associated with the disease. Following the introduction of multiple drug therapy (MDT) the number of registered patients has dropped dramatically worldwide. ${ }^{2}$ The leprosy bacillus was first recognized as such in 1873 by Hansen in Norway. The disease virtually disappeared in industrialized countries with improved socioeconomic conditions, but in developing countries it has continued unabated. ${ }^{1}$

In most infected people, the infection remains asymptomatic, but some people contract the disease and end up with potentially disfiguring deformities. Skin lesions may appear and heal spontaneously, becoming more frequent and severe as the disease progresses, ranging from hypo-pigmented patches to multiple nodules with extensive skin thickening and folding. Lesions of the nerves can lead indirectly to severe deformities, especially of the hands and feet.

There are approximately one million new cases annually. ${ }^{2}$ there are no estimates of the number of people with sub clinical infection. Two-three million people have leprosy-related deformities, with the lifeexpectancy of severely disabled persons reduced by $50 \%$, due mainly to economic hardship. ${ }^{2}$ There are currently an estimated 10-12 million cases of leprosy in the world. Nigeria has $40 \%$ of all registered leprosy cases in sub-Saharan Africa. ${ }^{3}$ The 18 countries in north western and western Africa have a leprosy prevalence rate that is twice that of central/eastern Africa and southern Africa. High endemic countries in Africa for leprosy are Gabon (2.13/1000), Central African Republic (2.44/1000), Congo (3.22/1000), Guinea (2.3/1000), and Mali (2.36/1000). ${ }^{3}$ 
Multidrug therapy (MDT) coverage has been low in Africa, so the prevalence of leprosy is not declining. $25-40 \%$ of new leprosy cases in Africa are children less than 15 years old. ${ }^{3}$ The drugs currently being used for MDT for leprosy are Rifampicin, Clofazimine and Dapsone for multibacillary leprosy, while Rifampicin alone is being used for paucibacillary leprosy. Casual contact with a patient with leprosy does not transmit $M$. leprae. Persons at most risk of leprosy are those who live in close physical contact with someone with leprosy. The mean incubation period is 3-5 years but has been as long as 20 years.

The long incubation period will account for new leprosy cases after $2000^{4}$. .In Sene District of the Brong Ahafo Region of Ghana where this study was conducted, the prevalence rate of leprosy is 2.4/10,000 of the population. In the Brong Region the prevalence rate of leprosy is $0.04 / 10,000$ of the population. This study aimed at determining the risk factors associated with leprosy in the community in the Sene District, in order to plan strategies to reduce the spread of the disease in the district.

\section{Background of the Study}

Sene District is the largest but one of the least developed district in terms of infrastructural development in Brong Ahafo Region. It covers an area of 8586 square kilometres with Kwame Danso as the district capital. The district is located on the Eastern part of the Brong-Ahafo Region. It shares common boundaries with Atebubu district to the West, to the North and East by the Lake Volta and to the South by Digya National Park and Sekyere district of the Ashanti Region.

The District has a projected population from the 2000 census of 90,696 , using a population growth rate of $2.5 \%$.The indigenous ethnic groups in the district are the Dwan, Bassa, Nkomi and Wiase. However, the District has a large population of settler farmers mostly of Northern extraction (Dagaaba, Dagombas, Konkombas, Baasare, Hausas and Wallas). In Sene District the number of patients with leprosy during the year 2006 was 24 giving a prevalence rate of $2.4 / 10,000$ of the population.

\section{MATERIALS AND METHOD}

\section{Type of study}

This is a case-control study Selected for the study were 24 patients between the ages of 9years to fifty six years who had been diagnosed with leprosy (cases) and 2 healthy persons (controls) for each case, who were matched according to sex, age, $(+/-5 y r s)$ and place of residence. Using close contact with known leprosy case as the exposure of concern, it was estimated based on the results of a previous cross-sectional study on leprosy carried out in the Sene District, that $60 \%$ of controls would have been exposed to a case of leprosy.

Estimates of $95 \%$ of the cases were also estimated to have had close contact with someone known to have leprosy. Using 21 cases and 42 controls ( 1 case to 2 controls) will be enough to detect difference between cases and controls with regards to exposure to leprosy cases, at a confidence interval of $95 \%$ and a power of $80 \%$. The forty eight (48) Controls were screened to ensure that they did not have any hypo-pigmented anaesthetic patches on any part of their body.

The presence of enlarged nerves and, thickened earlobes and plaque like lesions consistent with leprosy was also looked for. The cases were selected from a register of active leprosy cases. No new cases were found when screening for the controls. Scar on the right upper arm was used to identify those who have had BCG vaccination among the cases and the controls.

\section{Variables}

Among the factors investigated in the study were type of leprosy, contact with known leprosy case, duration of contact with the known leprosy case, presence or absence of BCG scar as a measure of BCG vaccination, and close contact with domestic animals.

\section{Data Analysis}

Data was double entered and analysed using the EPIInfo 3.3 software (CDC Atlanta). Cases and controls were compared by their contact someone with leprosy in the same house, contact with someone with leprosy but not in the same house, the duration of contact with known case of leprosy and the presence or absence of BCG scar.. Odds ratio and confidence intervals were calculated for each of these exposures, comparing the cases to the controls. A positive association was considered for any of the variables when $\mathrm{p}<0.05$ for confidence interval at $95 \%$.

\section{RESULTS}

There were twenty four (24) cases and forty eight controls (48). Eighteen (75\%) of the cases had paucibacillary leprosy and six $(25 \%)$ had multibacillary leprosy. Nine $(37.5 \%)$ had lesion on their upper limbs, $6(25 \%)$ of the cases had lesions on the trunk, Four $(16.7 \%)$ had it on their lower limbs, three (12.5\%) had it on both their upper and lower limbs and two (8.3\%) had it on their faces. The background characteristics of the cases and controls are comparable (Table 1). 
Table 1 Background characteristics of cases and controls

\begin{tabular}{|l|l|l|}
\hline \multicolumn{1}{|c|}{$\begin{array}{l}\text { Male } \\
\text { Female }\end{array}$} & CASES & CONTROL \\
\hline Sex & $\begin{array}{l}12(50 \%) \\
12(50 \%)\end{array}$ & $\begin{array}{l}24(50 \%) \\
24(50 \%)\end{array}$ \\
\hline Age Mean (SD) & $21.9(12.9)$ & $20.8(12.2)$ \\
\hline $\begin{array}{l}\text { Educational Status } \\
\text { Nil }\end{array}$ & $8(33.3 \%)$ & $13(27.1 \%)$ \\
Primary/JSS/MSL/SSS & $16(66.7 \%)$ & $35(72.9 \%)$ \\
\hline $\begin{array}{l}\text { Religion } \\
\text { Christian } \\
\text { Moslem/ Traditional/Other }\end{array}$ & $15(62.5 \%)$ & $31(64.6 \%)$ \\
\hline $\begin{array}{l}\text { Marital Status } \\
\text { Married } \\
\text { Single/Divorced/Widowed }\end{array}$ & $9(79.2 \%)$ & $17(35.4 \%)$ \\
\hline $\begin{array}{l}\text { Occupation } \\
\text { Pupil } \\
\text { Farmer/ Trader/Others }\end{array}$ & $16(33.3 \%)$ & $14(29.2 \%)$ \\
\hline
\end{tabular}

Table 2 Factors Associated with Leprosy

\begin{tabular}{|c|c|c|c|c|}
\hline Factors & Cases & Control & $\begin{array}{c}\text { Odds Ratio } \\
(95 \% \text { CI })\end{array}$ & P-value \\
\hline $\begin{array}{c}\text { Contact with someone with leprosy in } \\
\text { the same houses } \\
\text { Yes } \\
\text { No }\end{array}$ & $\begin{array}{l}14(58.3 \%) \\
10(41.7 \%)\end{array}$ & $\begin{array}{c}14(29.2 \%) \\
34(70.8 \%)\end{array}$ & $3.40(1.09-10.8)$ & 0.017 \\
\hline $\begin{array}{l}\text { Contact with someone with leprosy } \\
\text { but not in the same house } \\
\text { Yes } \\
\text { No }\end{array}$ & $\begin{array}{l}7(29.2 \%) \\
17(70.8 \%)\end{array}$ & $\begin{array}{l}28(58.3 \%) \\
20(41.7 \%)\end{array}$ & $0.29(0.09-0.94)$ & 0.019 \\
\hline
\end{tabular}

Table 2b Factors Associated with Leprosy

\begin{tabular}{|c|c|c|c|c|}
\hline Factors & Cases & Control & $\begin{array}{c}\text { Odds Ratio } \\
(95 \% \text { CI })\end{array}$ & P-value \\
\hline $\begin{array}{l}\text { Duration of contact with someone } \\
\text { with leprosy in the same house. } \\
\text { Up to } 5 \mathrm{yrs} \\
6 \mathrm{yrs}+\end{array}$ & $\begin{array}{l}4(28.6 \%) \\
10(71.4 \%)\end{array}$ & $\begin{array}{l}5(35.7 \%) \\
9(64.3 \%)\end{array}$ & $0.72(0.11-4.61)$ & 0.7 \\
\hline $\begin{array}{l}\text { Duration of contact with someone } \\
\text { with leprosy outside the house. } \\
\text { Up to } 5 y \text { rs } \\
6 y r s\end{array}$ & $\begin{array}{l}5(71.4 \%) \\
2(28.6 \%)\end{array}$ & $\begin{array}{l}23(82.1 \%) \\
5(11.9 \%)\end{array}$ & $0.54(0.06-5.5)$ & 0.8 \\
\hline $\begin{array}{c}\text { BCG Scar Absent } \\
\text { Yes } \\
\text { No }\end{array}$ & $\begin{array}{l}22(91.7 \%) \\
2(8.3 \%)\end{array}$ & $\begin{array}{l}24(50 \%) \\
24(50 \%)\end{array}$ & $11.0(2.5-76.2)$ & 0.0005 \\
\hline
\end{tabular}

\section{Contact with Domestic Animals}

There was no significant association between having leprosy and contact with common domestic animals namely dogs, cats, poultry, cattle and pigs.

\section{DISCUSSION}

Although the causative organism for leprosy is known, It is still unclear how the disease is transmitted and the other factors important in the disease causation. 
This study therefore tried to identify some factors associated with leprosy in the Sene District in order to implement an effective strategy to eliminate leprosy from the district.

There was no significant difference in the demographic background of the cases and controls. From this study $75 \%$ of the cases identified had paucibacillary leprosy. For the purposes of administering the multidrug therapy, leprosy patients are classified into either multibacillary or paucibacillary.

Multibacillary leprosy patients have six or more skin lesions and skin slit skin smear is usually positive for acid fast bacilli, paucibacillary leprosy patients usually have fewer than six skin lesions. Paucibacillary leprosy is said to be the active leprosy case. Paucibacillary leprosy is a reflection of leprosy contacts in the population $^{5}$. From the results of this study, with a higher proportion of the cases, none of whom have lived outside the Sene district, having paucibacillary leprosy; it is an indication that leprosy is endemic in the district. The age of the cases ranged from 9 to $56 y$ rs, with $13(54.2 \%)$ of them being less than twenty years. These findings are an indication of recent transmission and infection by Mycobacterium leprae in the district. There is therefore an urgent need for the district to identify all cases and treat them to break the transmission of infection.

Most of the lesions were found on the trunk (25\%) and upper limb (37.5\%). This means that screening within the community can be done with very little inconvenience to clients. A trained, observant field worker working in the communities can pick up cases easily. There is therefore the need to train all health workers, especially those who work in the communities to identify leprosy lesions.

The School Health Programme can also help tremendously in identifying cases. This is because from the study $14(58.3 \%)$ of the cases were pupils attending Primary School or JSS. Physical examination of children as part of the school health program will help identify cases at an early stage of the disease, for them to be treated to break the transmission and prevent the complications of leprosy.

From the study, contact with someone with leprosy in the same house is significantly associated with having leprosy (OR -3.4 95\%CI 1.09-10.8, p=0.017) .58.3\% of the cases in the study had close contact with someone with leprosy in the same house. Comparing this to the association between leprosy and contact with someone with leprosy in another house, it was found that only $29.2 \%$ of the cases had such contact (OR 0.29 95\%CI
0.09-0.94). This appears to confirm that casual contact with a patient with leprosy does not transmit M. leprae. Although the direct mode of transmission of Mycobacterium leprae to cause leprosy is uncertain, contact with someone with leprosy over a long period has been found to facilitate infection with leprosy. ${ }^{4}$ It is therefore important that all close contacts of leprosy patients especially those living in the same house as the patients are thoroughly examined as part of the overall management of cases of leprosy in the district.

The results of the study however showed that duration of contact was not significantly associated with developing leprosy (OR - 0.72 95\%CI 0.11-4.61). This is contrary to what is known from the literature .Selection bias can be the cause of this finding. The long incubation period of leprosy can mean that some of the controls chosen in the study are in the preclinical stage and are no different in terms of exposure compared to the cases. The average incubation period of leprosy is 3 to $5 y$ rs but may be as long as twenty years. ${ }^{6}$

The study showed a significant difference between the cases and controls with respect to the presence or absence of BCG scar on the right upper arm. Whereas only $8.3 \%$ of the cases had BCG scars, $50 \%$ of the controls were found to have BCG scars. This is an indication of the protection against leprosy conferred by $\mathrm{BCG}$ vaccination. (OR $1195 \% \mathrm{CI} 2.12-76.17 \mathrm{p}=$ 0.0005). This finding is similar to what has been observed in other studies which have shown that BCG confers some protection against leprosy. ${ }^{7,8,9}$

From one of such studies, the summary protective effects obtained from meta-analysis of trials, cohort studies and case-control studies of BCG vaccination and leprosy were 43 (27-55), 62 (53-69), and 59 (4668) percent respectively. ${ }^{10}$ Administrative coverage for BCG appear to be very high in Ghana and in the Sene District,(100\% respectively for 2007), This has been confirmed by an EPI cluster survey carried out in the Sene District in 2008 which found the coverage of BCG vaccine for children less than one year to be 99\%(CI 98.5\%-100.2\%).

Close contact with all the common domestic animals was not significantly associated with having leprosy. This confirms what is already known that the Mycobacterium leprae infect primarily man, it was in 1970 that the mycobacterium was first grown in captured wild armadillo from South America. ${ }^{11}$

The study was limited in its design that we could not assess the effect of socioeconomic and cultural factors on the development of leprosy. 
This is because the cases and controls did not differ much looking at their socioeconomic and cultural backgrounds.

The selection of the cases and controls is one of the limitations of this study since cases and controls were defined based on just physical examination. The use of BCG scar as a proxy for immunity acquired from BCG vaccination will also introduce a bias since not all children who develop scars from the vaccination acquire immunity.

\section{CONCLUSION}

This study shows that in the Sene District household contact with someone with leprosy is associated with having leprosy and BCG vaccination confers protection against leprosy. The implication of these findings for leprosy control in the District are that the District needs to maintain the high coverage of BCG vaccination in children and ensure that newborns are vaccinated with BCG as early as possible to prevent them from contracting the disease through household contacts.

There is the need for the district to ensure that all close contacts of identified leprosy cases are screened for signs of the disease and put on treatment if lesions are found. Health Workers in the District, especially those who work in the communities, should be trained to identify leprosy lesions. With these interventions, the District will be able to, in the long term, reduce cases of leprosy in the District.

\section{REFERENCE}

1. 1. Harboe $M$ Leprosy. In: Health and disease in developing countries, edited by Kari S. Lankinen, Staffan Bergstrom, P. Helena Makela, Miikka Peltomaa. London, England, Macmillan Press, 1994. : 255-64.

2. Noordeen SK, Hombach JM. In: Tropical Disease research: progress 1991-92. Eleventh programme report of the UNDP/World Bank/WHO Special Programme for Research and Training in Tropical Diseases (TDR) Geneva, Switzerland, World Health Organization (WHO), 1993:47-55.

3. Misra RS High endemic world regions for Leprosy. In: Leprosy a reference guide for medical practitioners, programme managers and leprosy workers (edited by) RS Misra, New Delhi, India, Concept Publishing 1993: 41-50.

4. WHO in action. Eliminating leprosy World Health Mar-Apr 1994;47(2):30-1.

5. Chisi JE, Nkhoma A, Zverev Y, Misiri H, Komolafe OO Leprosy in Nkhotakota District Hospital, East African Medical Journal 2003 Dec;80(12):635-639

6. Bertolli JM, Ann Arbor, A case-control study of the effectiveness of BCG vaccine for preventing clinical leprosy in Yangon, Myanmar Michigan, University Microfilms International, 1994. xviii, 186 p. Order No. 9509870

.7. Zodpey SP The BCG controversy: a reappraisal of the protective effect against tuberculosis and leprosy Indian Journal of Public Health Apr -Jun 2004;48(2):70-77

8. Ponnighaus JM, Fine PE, Sterne JA, Wilson RJ, Msosa E, Gruer PJ, Jenkins PA, Lucas SB, Liomba NG and Bliss L Efficacy of BCG vaccine against leprosy and tuberculosis in northern Malawi. Lancet. 1992; 339(8794):636-9.

9. Lombardi C, Pedrazzani ES, Pedrazzani JC, Ferreira Filho $\mathrm{P}$ and Zicker $\mathrm{F}$ Protective efficacy of BCG against leprosy in Sao Paulo, Brazil. [Eficacia protectora del BCG contra la lepra en Sao Paulo, Brasil.] Bol Oficina Sanit Panam. 1995 Nov; 119(5):415-21

10. Noordeen SK and Sansarricq H. Immunization against leprosy: progress and prospects. Bulletin of the Pan-American Health Organization 1984;18 (3):295-9. 